Bangladesh J. Bot. 49(3): 531-540, 2020 (September)

\title{
CHEMICAL COMPOSITION, ANTIOXIDANT AND ANTIBACTERIAL ACTIVITIES OF ESSENTIAL OIL OF CURCUMA PHAEOCAULIS VALETON
}

\author{
Heng Liang, Qian Wang ${ }^{1}$, Chunbang Ding, Li Zhang ${ }^{2}$ and Ruiwu Yang* \\ College of Life Science, Sichuan Agricultural University, No. 46, Xinkang Road, \\ Yaan, Sichuan, 625014, P.R. China
}

\begin{abstract}
Keywords: Curcuna phaeocaulis, Chemical composition, Essential oil, Antioxidant activity, Antibacterial activity
\end{abstract}

\begin{abstract}
Chemical composition, antioxidant and antibacterial activities of the essential oil of Curcuma phaeocaulis were analysed. In the aerial part, 22 compounds account for $69.23 \%$ of the total essential oil and authenticated, while in the underground part, 32 compounds account for $84.28 \%$ of the total essential oil and authenticated. Among the compounds detected, $\alpha$-pinene, camphene, eucalyptol, camphor, borneol, $\beta$ tumerone, epi-curzerenone were the main compounds of volatile oil in both parts of Curcuma phaeocaulis. In addition, various lipid antioxidant properties by peroxidation assays, inoxidizability and antibacterial action were assessed. The result may be considered as a baseline study for the further development and application of Curcuma phaeocaulis.
\end{abstract}

\section{Introduction}

Curcuma is an important genus belonging to Zingiberaceae and this plant group is widely used in medical, food, chemical and ornamental. There were about 120 plant species in this family (Záveská 2012). Out of them 10 species of Curcuma were found in China (Xiao et al. 1997, Wu 2008, Chen and Xia 2010). There are books which recorded that Curcuma phaeocaulis was used as Chinese traditional herbal medicine with a history of more than a thousand years. In traditional Chinese medicine (TCM), Rhizoma Curcumae was the rhizomes of $C$. phaeocaulis. Recent studies have shown that people use some extract of $C$. phaeocaulis to process activity experiment and obtained the predictive effect (Hou et al. 2015). Lipids belonging to a group of naturally occurring molecules was used as diet in the daily lives. Sometimes lipids might occur some undesirable direction such as oxidation and lipolysis (Kinderlerer and Johnson 1992). Lipid peroxidation decrease many food products nutritional value and food safety. Moreover, it also changes foods' color, quality and taste. Food products under environmental exposure gave rise to a free radical process, and might give rise to auto-oxidation of polyunsaturated lipids. Assuming the use of antioxidants that can inhibit the activity of free radical oxidation is practical in preventing grease deterioration.

In order to prevent oxidative degradation of foods, antioxidants as a food additive are widely used in food product (Jiang and Xiong 2016). Many antioxidants are synthetic chemicals, which have serious side effects, although they usually have a strong radical scavenger (Imaida et al. 1983). Therefore, the antioxidants which obtained naturally become an innovation and research focus in recent years. $C$. longa (turmeric) is a perennial herb, which is used as folk medicine in many disease treatments for a long time. More than that, its oils often is used as spice, textiles and cosmetics (Mahendra and Bisht 2011). In India, turmeric rhizomes are used as medicine too. Previously many studies showed that turmeric is used in clinical treatment to against cancer, AIDS

*Author for correspondence:< yrwu@ @icau.edu.cn>. ${ }^{1}$ The Olive Department of Economic Forest Research Institute of Longnan City. ${ }^{2}$ College of Science, Sichuan Agricultural University, China. 
and so on (Prasad et al. 2015, Azuine and Bhide 2016, Feng et al. 2017). The volatile compounds extracted from Curcuma had a good biological activity (Hwang et al. 2000, Wilson et al. 2005, Sathishkumar et al. 2010, Jena et al. 2017).

In the present study, the essential oils, chemical composition and functional activities in both aerial- and underground part of $C$. phaeocaulis were analysed. This work will provide a good guidance for the use of $C$. phaeocaulis.

\section{Materials and Methods}

Both aerial- and underground part of Curcuma phaeocaulis were collected from Sichuan Province, China. The plant materials were identified by Prof. Ruiwu Yang from the Department of Botany of Sichuan Agricultural University and the specimens were deposited in Sichuan Agricultural University. The experiment was carried out in the Laboratory of Resource Plant, Department of Botany, College of Life Science, Sichuan Agricultural University.

The aerial- and underground part of $C$. phaeocaulis were separated and washed. Then, each part was air dried in dark at room temperature. The dried materials were ground to thinly grated in a grinder and sun dried. According to the aerial- and underground part, respectively pulverized into a fine powder. Gas chromatography mass spectrometry (GCMS-QP2010) was used to analyze chemical components. The processed materials were placed in a Soxhlet extraction apparatus for $5 \mathrm{hrs}$ and extracted three times with hexane. The extracted oils with a light-yellow color and the oils yield $1.03 \%$ for aerial part and $3.34 \%$ for underground part. The extracted oils were dried over anhydrous sodium sulfate and stored at $4^{\circ} \mathrm{C}$.

The GCMS technique used to analyze the chemical composition of essential oils which was extracted from both aerial- and underground parts of $C$. phaeocaulis materials. The GCMS analyses were performed using gas chromatography mass spectrometry instrument island ferry company GCMS-QP2010 and equipped with a Perkin Elmer Elite-5MS capillary column (5\% phenylmethyl siloxane, length $30 \mathrm{~m} \times$ inner diameter $0.25 \mathrm{~mm} \times$ film thickness $0.25 \mu \mathrm{m}$ ). Separately, the injector and interphase were set at the same temperatures at $280^{\circ} \mathrm{C}$, the ion source temperatures were maintained at $230^{\circ} \mathrm{C}$ and selective mass detector temperatures was $150^{\circ} \mathrm{C}$. Helium was the carrier gas and the flow rate is $1.0 \mathrm{ml} / \mathrm{min}$. Different parts of C. phaeocaulis materials had different oven temperature. The essential oil from underground part, the GC oven temperature was kept at $60^{\circ} \mathrm{C}$ for $1 \mathrm{~min}$, and then increase programmed from 6 to $185^{\circ} \mathrm{C}$ at the rate of $1.5^{\circ} \mathrm{C} / \mathrm{min}$ and kept at $185^{\circ} \mathrm{C}$ for $1 \mathrm{~min}$, and then the GC oven temperature was kept at $60^{\circ} \mathrm{C}$ for $1 \mathrm{~min}$, and then increase programmed from 18 to $275^{\circ} \mathrm{C}$ at the rate of $9^{\circ} \mathrm{C} / \mathrm{min}$ and kept at $275^{\circ} \mathrm{C}$ for $2 \mathrm{~min}$. The essential oil from aerial part, the $\mathrm{GC}$ oven temperature was kept at $80^{\circ} \mathrm{C}$ for $0 \mathrm{~min}$, and then increase programmed from 8 to $280^{\circ} \mathrm{C}$ at the rate of $10^{\circ} \mathrm{C} / \mathrm{min}$ and kept at $280^{\circ} \mathrm{C}$ for 40 min. Using the normalization method from the GC peak areas to computed the percentage composition of the oils, and all results were performed in triplicate and averaged.

In the free radicals 2,2-diphenyll-picrylhydroazyl (DPPH) radical scavenging assay, the method of Yang et al. was followed with some modifications (Yang et al. 2009). In a assay, 2.0 $\mathrm{ml}$ different concentrations gradient $(0,0.2,0.4,0.6,0.8,1.0 \mathrm{mg} / \mathrm{ml}$ in $95 \%$ ethanol) and $2.0 \mathrm{ml}$ DPPH solution $(0.1 \mathrm{mmol} / \mathrm{l}$ in $95 \%$ ethanol) were mixed in the reaction solution in the tubes. After mixing, the solution was left for $60 \mathrm{~min}$ at room temperature. The DPPH radical inhibition could be measured by using a spectrometer (UV-1750, Shimadzu, Kyoto, Japan) reader in $517 \mathrm{~nm}$. This experiment was repeated three times and then the data needed to average. Vc was treated as control. The capability to scavenge the DPPH radical was given by:

Scavenging ability $(\%)=\left(1-\mathrm{A}_{\text {sample }} / \mathrm{A}_{\mathrm{DPPH}}\right) \times 100$ 
where the absorbance value of $\mathrm{A}_{\text {sample }}$ was mixed solution of DPPH solution and related tested samples, and $\mathrm{A}_{\mathrm{DPPH}}$ was blank consisted of only ethanol.

In the hydroxyl radicals scavenging activity assay, the method of Jiang et al. was as followed with some modifications (Jiang et al. 2015). In a assay, $1.0 \mathrm{ml} \mathrm{H}_{2} \mathrm{O}_{2}\left(0.1 \%\right.$,), $1.0 \mathrm{ml}$ of $\mathrm{FeSO}_{4}$ $(0.75 \mathrm{mmol} / \mathrm{l}), 2.0 \mathrm{ml}$ of PBS (pH 7.4) and $2.0 \mathrm{ml}$ different concentrations gradient $(0,0.2,0.4$, $0.6,0.8,1.0 \mathrm{mg} / \mathrm{ml}$ in $95 \%$ ethanol) sample solution were mixed in the reaction solution. After mixing, the solution was left for $60 \mathrm{~min}$ at $37^{\circ} \mathrm{C}$. The Hydroxyl radicals scavenging activity could be measured by using a spectrometer (UV-1750, Shimadzu, Kyoto, Japan) reader in $510 \mathrm{~nm}$. This experiment was repeated 3 times and then the data needed to average. Vc is as a control. The capability to scavenge the hydroxyl radical was given by:

Scavenging ability $(\%)=\left(\mathrm{A}_{\text {sample }}-\mathrm{A}_{\text {blank }}\right) /\left(\mathrm{A}_{\text {control }}-\mathrm{A}_{\text {blank }}\right) \times 100$

where, the absorbance value of $\mathrm{A}_{\text {sample }}, \mathrm{A}_{\text {control }}$ and $\mathrm{A}_{\text {blank }}$ were presence of sample, blank without of $\mathrm{H}_{2} \mathrm{O}_{2}$ and the absence of sample, respectively.

In the superoxide radical scavenging ability assay was assessed following the method of Liu et al. (2009) with some modifications. In an assay, $1.0 \mathrm{ml}$ Tris- $\mathrm{HCl}(16 \mathrm{mmol} / \mathrm{l}, \mathrm{pH} 8.0)$ and 1.0 $\mathrm{ml}$ sample solution $(0,0.2,0.4,0.6,0.8,1.0 \mathrm{mg} / \mathrm{ml}$ in $95 \%$ ethanol) were prepared in first. And then $468 \mu \mathrm{mol} / \mathrm{l} \mathrm{NADH}, 60 \mu \mathrm{mol} / 1 \mathrm{PMS}$ and $468 \mu \mathrm{mol} / \mathrm{l} \mathrm{NBT}$ were prepared in $1.0 \mathrm{~mL}$ Tris- $\mathrm{HCl}$ buffer. After mixing, the solution was left for $5 \mathrm{~min}$ at $25^{\circ} \mathrm{C}$, the superoxide-radical scavenging ability could be measured by using a UV-spectrophotometer (UV-1750, Shimadzu, Kyoto, Japan) reader in $560 \mathrm{~nm}$. This experiment was 3 times repeated and then the data needed to average. Vc was treated as control. The capability to scavenge the hydroxyl radical was given by:

Scavenging ability $(\%)=\left(1-\mathrm{A}_{\text {sample }} / \mathrm{A}_{\text {blank }}\right) \times 100 \%$

where, the average absorbance value about $A_{\text {sample }}$ and $A_{\text {blank }}$ were the sample and the absence of sample, respectively.

The measurement of FRAP was assessed following the method of Yuan et al. (2005) used with some modifications. In a assay, $2.5 \mathrm{ml} \mathrm{PBS}(0.2 \mathrm{~mol} / \mathrm{l}, \mathrm{pH} 6.6), 2.5 \mathrm{ml}$ sample solution (0, $0.1,0.5,1.0,1.5,2.0 \mathrm{mg} / \mathrm{ml}$ in $95 \%$ ethanol) and $1.0 \mathrm{ml}$ of potassium ferricyanide $\left[\mathrm{K}_{3} \mathrm{Fe}(\mathrm{CN})_{6}\right]$ $(1 \%, \mathrm{w} / \mathrm{v})$ were mixed in the reaction solution. After mixing, the solution was left for $20 \mathrm{~min}$ at $50^{\circ} \mathrm{C}$. The mixed solution was centrifuged at $3000 \mathrm{r} / \mathrm{pm}$ for $10 \mathrm{~min}$ and it was kept for cooling. Next $2.5 \mathrm{ml}$ trichloroacetic acid [TCA] $(10 \%, \mathrm{w} / \mathrm{v})$ was added in the solution. In a test tube, the $0.5 \mathrm{ml}$ ferric chloride $\left[\mathrm{FeCl}_{3}\right]$ and $2.5 \mathrm{ml}$ of absolute ethyl alcohol were mixed with the $2.5 \mathrm{ml}$ supernatant. After mixing the mixture it was kept for $10 \mathrm{~min}$. Then the absorbance was measured by using a UV-spectrophotometer at $700 \mathrm{~nm}$. Increase in absorbance of the reaction mixture indicated increase in reducing power. This experiment was repeated for 3 times and was averaged. Vc was treated as a control.

Agar well diffusion method was used to evaluate the antimicrobial activity of zedoary turmeric oil extracted from the samples, namely. Staphylococcus aureus and Bacillus cereus (two Gram-positive bacterial strains) and Salmonella and Escherichia coli (two Gram-negative bacterial strains) were used to test it. All strains obtained from the Department of Biochemistry and Molecular Biology, Sichuan Agriculture University.

Nutrient agar $(18 \mathrm{~g})$ was dissolved in distilled water for 1.0 litre and the $\mathrm{pH}$ was adjusted to 7.0 in the nutrient agar aqueous solution. Before test, the autoclave was used for sterilizing all glass wares and media in $15 \mathrm{psi}$ at $121^{\circ} \mathrm{C}$ for $21 \mathrm{~min}$. The required concentrations $(0.2,0.4,0.6$, 0.8 and $1.0 \mathrm{mg} / \mathrm{ml}$ ) were needed to give appropriate dilutions about the essential oil which were accurately weighted and dissolved in sterile $95 \%$ ethanol. The prepared solutions were stored at $-20^{\circ} \mathrm{C}$. The agar well diffusion method showed the antimicrobial activity about the turmeric oil of C. phaeocaulis. In a laminar airflow, the inoculation was carried out in all the trials. The 
inoculated nutrient agar plate needed to cool before inoculation. Swabbing method was used to inoculate the bacterial strains. Holes punch a diameter of $6 \mathrm{~mm}$ and a spacing of $4 \mathrm{~cm}$ were prepared in the medium using sterilized cork drillers to prepare four uniform holes in each well. The base of each hole was sealed with a drop of molten nutrient agar. To fill these wells the micropipette was used with $50 \mu \mathrm{l}$ of essential oil and let them diffuse for $40 \mathrm{~min}$. All the inoculated plates were incubated in the incubator at $37^{\circ} \mathrm{C}$ for $24 \mathrm{hrs}$ to determine the antimicrobial activity. The diameter of the inhibition zone produced by the essential oil around the well indicated the antimicrobial activities. This experiment was also carried out 3 times for each sample to evaluate of antimicrobial activity.

The bacteriostatic circle standard (Paulo et al. 2010): inhibitory zone diameter greater than 20 $\mathrm{mm}$, supersensitive; $15-20 \mathrm{~mm}$, hypersensitive; $10-15 \mathrm{~mm}$, the sensitive; $7-9 \mathrm{~mm}$, low sensitive, less-than $7 \mathrm{~mm}$, resistant.

\section{Results and Discussion}

The chemical compostion of the essential oil of aerial part (AP) and underground part (UP) of Curcuma phaeocaulis is presented in Table 1. About 32 components were identified in the underground part essential oil representing about $84.28 \%$ of the total amount and 22 components were identified in aerial part essential oil constituting about $69.23 \%$ of the total weight. The major components were germacron (16.89\%), epi-curzerenone (16.35\%), $\beta$-tumerone $(6.47 \%)$, camphor (5.11\%), borneol (5.03), eucalyptol (4.96\%), ar-tumerone (4.46\%) and ar-curcumene (4.11\%). In underground part essential oil of $C$. phaeocaulis, were eucalyptol (28.68\%), camphor (4.31\%), epi-curzerenone (3.68\%), borneol (3.66\%), $\beta$-Pinene (3.27\%), and L-linalool $(3.02 \%)$ in aerial part essential oil of $C$. phaeocaulis.

It is interesting to note that a major component in the essential oil germacron (16.89\%) and epi-curzerenone (16.35\%) from underground part while a very minor quantity in the essential oil germacron $(0.86 \%)$ and epi-curzerenone $(3.68 \%)$ of the aerial part. The contents of $\alpha$-pinene (2.34\%), $\beta$-pinene (3.27\%), D-limonene (2.34\%), eucalyptol (28.68\%) and $\beta$-elemene (2.72\%) in underground part are very less and a half of the amount found in aerial part.

In $517 \mathrm{~nm}$, the DPPH as a stable free radical has a characteristic absorption maximum. As a tool, it is used to assessing the DPPH free radical scavenging activity of antioxidants and is widely accepted (Hua et al. 2014, Milella et al. 2014, Xie et al. 2014, Musa et al. 2016). DPPH free radicals are scavenged by the fact that natural compounds can transfer electrons or hydrogen atom to DPPH (Naik et al. 2003). During this reaction, the absorbance decreases and the solution changes from purple to pale yellow. Compared with Vc (controlling standard), the results showed that the different concentrations of essential oil had different DPPH scavenging abilities (Fig. 1). The essential oil of underground part showed stronger activity than the essential oil of dry aerial part. $1.0 \mathrm{mg} / \mathrm{ml}$, scavenging ability on DPPH radical are keeping balance at underground part $(86.37 \%)$ and aerial part (74.16\%). The underground part essential oil was close to Vc. In this study, the essential oil showed a high scavenging ability in all concentration gradients. This finding was found to be similar with report of Zaeoung et al. (2005).

The ferrous ion chelating effect of the extracts by $\mathrm{Fe}^{+2}$ ferrozine test is presented shown in Fig. 2. The red decreased, the reason is that when in the presence of ion chelating substances, the ferrozine can quantitatively form complex with $\mathrm{Fe} 2+$ and the complex formation is disrupted. A higher absorbance value means that the reduction capacity of the sample is stronger, and according to the reduction capacity of the compound, the color of the mixture will change from yellow to blue or green. Among the tested substances, essential oil of underground part showed higher $\mathrm{Fe}^{2+}$ chelating ability than that of aerial part. When the concentration is $2.0 \mathrm{mg} / \mathrm{ml}$, the ferrous ion chelating capacity is the strongest and close to Vc. 
Table 1. Chemical composition of the essential oil of aerial part (AP) and underground part (UP) of Curcuma phaeocaulis.

\begin{tabular}{|c|c|c|c|c|c|}
\hline No. & Compound & Mol. Form & UP (\%) & $\mathrm{AP}(\%)$ & Identification \\
\hline 1 & $\alpha$-pinene & $\mathrm{C}_{10} \mathrm{H}_{16}$ & 1.02 & 2.34 & MS, RI, co-GC \\
\hline 2 & Camphene & $\mathrm{C}_{10} \mathrm{H}_{16}$ & 2.03 & 2.08 & MS, RI, co-GC \\
\hline 3 & $\beta$-phellandrene & $\mathrm{C}_{10} \mathrm{H}_{16}$ & - & 0.48 & MS, RI, co-GC \\
\hline 4 & $\beta$-pinene & $\mathrm{C}_{10} \mathrm{H}_{16}$ & 0.62 & 3.27 & MS, RI, co-GC \\
\hline 5 & $\beta$-myrcene & $\mathrm{C}_{10} \mathrm{H}_{16}$ & - & 0.33 & MS, RI, co-GC \\
\hline 6 & Carene & $\mathrm{C}_{10} \mathrm{H}_{16}$ & 0.11 & - & MS, RI \\
\hline 7 & D-limonene & $\mathrm{C}_{10} \mathrm{H}_{16}$ & 0.06 & 2.34 & MS, RI \\
\hline 8 & Limonene & $\mathrm{C}_{10} \mathrm{H}_{16}$ & 0.56 & - & MS, RI \\
\hline 9 & Eucalyptol & $\mathrm{C}_{10} \mathrm{H}_{18} \mathrm{O}$ & 4.96 & 28.68 & MS, RI \\
\hline 10 & Linalool & $\mathrm{C}_{10} \mathrm{H}_{18} \mathrm{O}$ & 0.07 & - & MS, RI \\
\hline 11 & L-linalool & $\mathrm{C}_{10} \mathrm{H}_{18} \mathrm{O}$ & - & 3.02 & MS, RI \\
\hline 12 & Camphor & $\mathrm{C}_{10} \mathrm{H}_{16} \mathrm{O}$ & 5.11 & 4.31 & MS, RI \\
\hline 13 & Isobornoel & $\mathrm{C}_{10} \mathrm{H}_{18} \mathrm{O}$ & 2.82 & 1.08 & MS, RI \\
\hline 14 & Borneol & $\mathrm{C}_{10} \mathrm{H}_{18} \mathrm{O}$ & 5.03 & 3.66 & MS, RI \\
\hline 15 & Terpinene & $\mathrm{C}_{10} \mathrm{H}_{18} \mathrm{O}$ & 0.59 & - & MS, RI \\
\hline 16 & Terpineol & $\mathrm{C}_{10} \mathrm{H}_{18} \mathrm{O}$ & 0.58 & 0.11 & MS, RI \\
\hline 17 & 2-pinen-10-ol & $\mathrm{C}_{10} \mathrm{H}_{18} \mathrm{O}$ & 2.53 & 1.08 & MS, RI \\
\hline 18 & $\delta$-elemene & $\mathrm{C}_{15} \mathrm{H}_{24}$ & 1.59 & - & MS, RI \\
\hline 19 & $\beta$-elemene & $\mathrm{C}_{15} \mathrm{H}_{24}$ & 0.42 & 2.72 & MS, RI \\
\hline 20 & $\alpha$-cedrene & $\mathrm{C}_{15} \mathrm{H}_{24}$ & 0.89 & - & MS, RI \\
\hline 21 & $\beta$-cedrene & $\mathrm{C}_{15} \mathrm{H}_{24}$ & 0.36 & - & MS, RI \\
\hline 22 & Caryophyllene & $\mathrm{C}_{15} \mathrm{H}_{24}$ & 0.81 & 1.93 & MS, RI \\
\hline 23 & $\gamma$-elemene & $\mathrm{C}_{15} \mathrm{H}_{24}$ & 0.43 & - & MS, RI \\
\hline 24 & ar-curcumene & $\mathrm{C}_{15} \mathrm{H}_{24}$ & 4.11 & - & MS, RI \\
\hline 25 & $\alpha$-longipinene & $\mathrm{C}_{15} \mathrm{H}_{24}$ & 0.22 & - & MS, RI \\
\hline 26 & $\alpha$-gurjunene & $\mathrm{C}_{15} \mathrm{H}_{24}$ & 0.17 & - & MS, RI \\
\hline 27 & Elemol & $\mathrm{C}_{15} \mathrm{H}_{26} \mathrm{O}$ & 1.62 & 0.72 & MS, RI \\
\hline 28 & Caryophyllene oxide & $\mathrm{C}_{15} \mathrm{H}_{24}$ & - & 1.76 & MS, RI \\
\hline 29 & $\alpha$-elemene & $\mathrm{C}_{15} \mathrm{H}_{24}$ & 0.78 & 2.01 & MS, RI \\
\hline 30 & $\alpha$-caryophyllene & $\mathrm{C}_{15} \mathrm{H}_{24}$ & 0.46 & - & MS, RI \\
\hline 31 & $\beta$-tumerone & $\mathrm{C}_{15} \mathrm{H}_{20} \mathrm{O}$ & 6.47 & 2.01 & MS, RI \\
\hline 32 & Cedrol & $\mathrm{C}_{15} \mathrm{H}_{26} \mathrm{O}$ & 1.03 & - & MS, RI \\
\hline 33 & Epi-curzerenone & $\mathrm{C}_{15} \mathrm{H}_{28} \mathrm{O}_{2}$ & 16.35 & 3.68 & MS, RI \\
\hline 34 & Eudesmol & $\mathrm{C}_{15} \mathrm{H}_{26} \mathrm{O}$ & 1.13 & - & MS, RI \\
\hline 35 & Ar-tumerone & $\mathrm{C}_{21} \mathrm{H}_{20} \mathrm{O}_{6}$ & 4.46 & 0.76 & MS, RI \\
\hline \multirow[t]{2}{*}{36} & Germacron & $\mathrm{C}_{15} \mathrm{H}_{22} \mathrm{O}$ & 16.89 & 0.86 & MS, RI \\
\hline & Total & & 84.28 & 69.23 & \\
\hline
\end{tabular}

The retention index (RI) was calculated using a homologous series of n-alkanes C10-C21. Percentages are the mean of three runs and were obtained from electronic integration measurements using selective mass detector. ${ }^{\text {aCO}}$-GC: Co-injection with an authentic sample. 


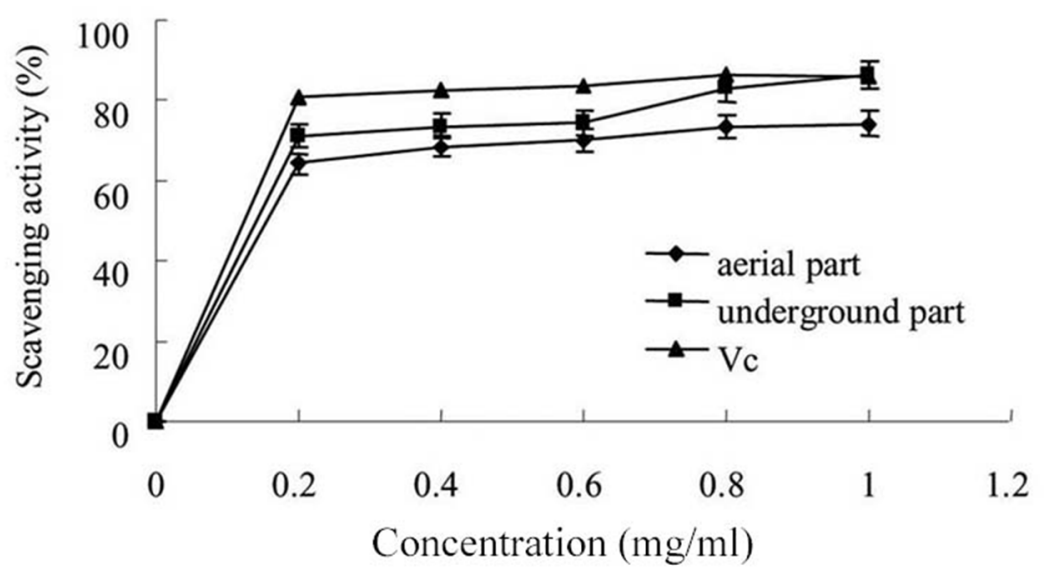

Fig. 1. Radical scavenging effect of Curcuma phaeocaulis essential oil on 2,2'-diphenyl-1-picrylhydrazyl radical.

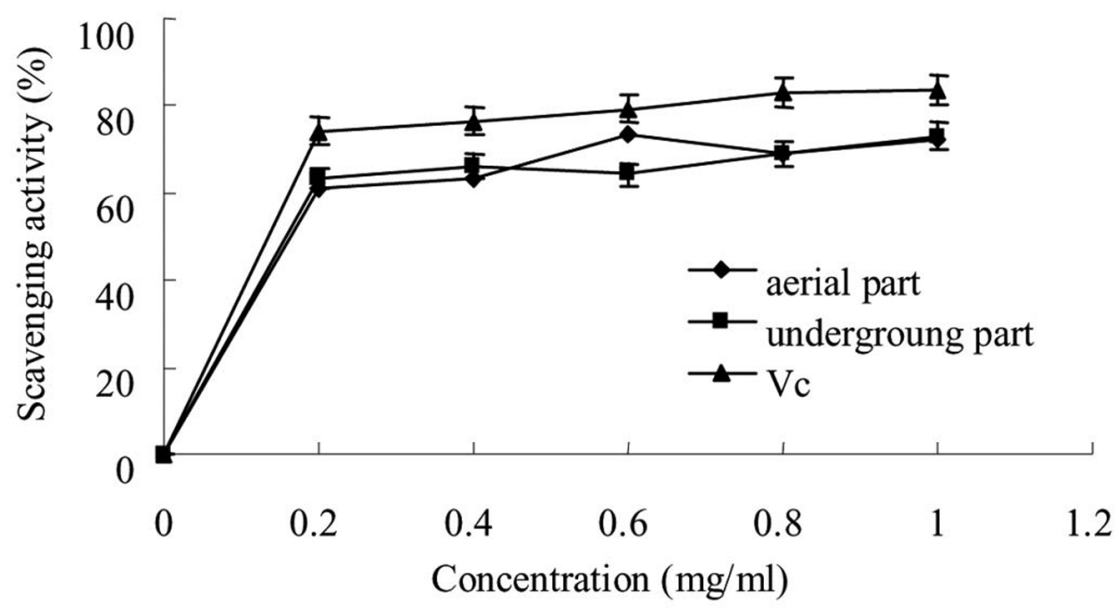

Fig. 2. Radical scavenging effect of Curcuma phaeocaulis essential oil on hydroxyl radical.

Hydroxyl radicals are extremely potent oxidants with the ability to cross cell membranes, readily react with most biomolecules, and may damage cells and tissues by Fenton reaction to produce hydroxyl radicals. To protect the tissues from oxidative damage, removal of hydroxyl radicals is a good way (Galano et al. 2011, Kryston et al. 2011). The scavenging activity is concentration dependent, with sample concentrations ranging from 0 to $1.0 \mathrm{mg} / \mathrm{ml}$ (Fig. 3). When the concentration reached $1.0 \mathrm{mg} / \mathrm{ml}$, the hydroxyl radical scavenging capacity remain balance in the underground part of $73.12 \%$ and aerial part of $72.19 \%$. The results showed that the essential oil had strong ability to scavenge hydroxyl radical, and the underground part was close to aerial part.

In different reactive oxygen species, the superoxide anion generated first. It acts as a precursor of singlet-oxygen and hydroxyl radicals, has greater oleophilic and oxidative ability. It is necessary to scavenge superoxide radical. The superoxide radical can induce arthritis and 
Alzheimer's disease (Mateen et al. 2016), the reason is the superoxide radical can induce lipid peroxidation and cause extensive cellular damage by contributing to the production of highly reactive radical species (Athukorala et al. 2006). Fig. 4 shows the superoxide anion-scavenging activity. The PMS/NADM system can assay in the reduction of NBT, and it is used to measure the superoxide anion-scavenging ability. At all tested concentrations, the scavenging activity of essential oils followed a dose-dependent pattern. In the underground part and aerial part, the superoxide radical scavenging effects were 83.92 and $76.21 \%$, respectively at the same concentration of $1.0 \mathrm{mg} / \mathrm{ml}$. In addition, the results showed that the essential oil had an obvious scavenging activity of superoxide radical.

The essential oil extract in underground part and aerial part of C. phaeocaulis was suitable for testing the antibacterial activities against Gram-positive bacterial strains (Staphylococcus aureus and Bacillus cereus) and Gram-negative bacterial strains (Salmonella and Escherichia coil). Tables 2 and 3 showed that the essential oil of underground part had stronger activity than that of aerial part. When concentration reached $1.0 \mathrm{mg} / \mathrm{ml}$, the aerial part essential oil reached a very sensitive to Escherichia coli , and the underground part to Staphylococcus aureus, Salmonella and Escherichia coil.

Table 2. Antibacterial activity of aerial part essential oil of Curcuma phaeocaulis.

\begin{tabular}{llllll}
\hline \multirow{2}{*}{ Test bacteria } & \multicolumn{5}{c}{ Inhibition zone $(\mathrm{mm})$} \\
\cline { 2 - 6 } & $0.2(\mathrm{mg} / \mathrm{ml})$ & $0.4(\mathrm{mg} / \mathrm{ml})$ & $0.6(\mathrm{mg} / \mathrm{ml})$ & $0.8(\mathrm{mg} / \mathrm{ml})$ & $1.0(\mathrm{mg} / \mathrm{ml})$ \\
\hline Staphylococcus aureus & $7.93 \pm 0.02 \mathrm{a}$ & $9.32 \pm 0.03 \mathrm{~b}$ & $11.00 \pm 0.07 \mathrm{c}$ & $13.56 \pm 0.04 \mathrm{~d}$ & $14.67 \pm 0.05 \mathrm{e}$ \\
Bacillus cereus & $7.63 \pm 0.05 \mathrm{a}$ & $7.65 \pm 0.02 \mathrm{a}$ & $9.21 \pm 0.04 \mathrm{~b}$ & $10.21 \pm 0.08 \mathrm{c}$ & $11.34 \pm 0.08 \mathrm{~d}$ \\
Salmonella & $8.23 \pm 0.01 \mathrm{a}$ & $8.85 \pm 0.05 \mathrm{~b}$ & $8.86 \pm 0.04 \mathrm{~b}$ & $9.12 \pm 0.03 \mathrm{c}$ & $9.43 \pm 0.02 \mathrm{~d}$ \\
Escherichia coli & $9.16 \pm 0.05 \mathrm{a}$ & $10.44 \pm 0.08 \mathrm{~b}$ & $12.19 \pm 0.07 \mathrm{c}$ & $14.21 \pm 0.08 \mathrm{~d}$ & $15.34 \pm 0.02 \mathrm{e}$ \\
\hline
\end{tabular}

Table 3. Antibacteria activity of the underground part of Curcuma phaeocaulis.

\begin{tabular}{llllll}
\hline \multirow{2}{*}{ Test bacteria } & \multicolumn{5}{c}{ Inhibition zone $(\mathrm{mm})$} \\
\cline { 2 - 6 } & $0.2(\mathrm{mg} / \mathrm{ml})$ & $0.4(\mathrm{mg} / \mathrm{ml})$ & $0.6(\mathrm{mg} / \mathrm{ml})$ & $0.8(\mathrm{mg} / \mathrm{ml})$ & $1.0(\mathrm{mg} / \mathrm{ml})$ \\
\hline Staphylococcus aureus & $9.23 \pm 0.03 \mathrm{a}$ & $11.29 \pm 0.03 \mathrm{~b}$ & $12.96 \pm 0.04 \mathrm{c}$ & $14.12 \pm 0.04 \mathrm{~d}$ & $15.89 \pm 0.08 \mathrm{e}$ \\
Bacillus cereus & $9.17 \pm 0.02 \mathrm{a}$ & $12.02 \pm 0.04 \mathrm{~b}$ & $14.21 \pm 0.03 \mathrm{c}$ & $14.36 \pm 0.04 \mathrm{~d}$ & $14.38 \pm 0.05 \mathrm{~d}$ \\
Salmonella & $11.27 \pm 0.02 \mathrm{a}$ & $12.43 \pm 0.05 \mathrm{~b}$ & $13.26 \pm 0.03 \mathrm{c}$ & $15.18 \pm 0.02 \mathrm{~d}$ & $15.21 \pm 0.02 \mathrm{~d}$ \\
Escherichia coli & $11.39 \pm 0.05 \mathrm{a}$ & $11.41 \pm 0.02 \mathrm{a}$ & $13.26 \pm 0.04 \mathrm{~b}$ & $15.29 \pm 0.08 \mathrm{c}$ & $16.37 \pm 0.02 \mathrm{~d}$ \\
\hline
\end{tabular}

From GC-MS data, it was clear that the major constituent's amount of epi-curzerenone and germacron in aerial part essential oil is less than that of the underground part. The presence of the compounds in major quantity might be due to the activity of underground part higher than aerial part. The lack of antioxidant activity during growth indicated that the beneficial pharmacological activity was bound to decrease. In other words, the underground part of $C$. phaeocaulis should be the first choice for medical, domestic and other purposes.

It is well known that the active principle in turmeric is a group of phenolic compounds including curcumin which has antioxidant activity (Kocaadam and Şanlier 2017). The acurcuminoids of turmeric has a strong antioxidant activity in some report (Barclay et al. 2000, Zaeoung et al. 2005, Nevin 2017). The present finding clearly showed that the essential oil form 
turmeric is an effective antioxidant. The main component of essential oil is curcumenol and alphazingiberene. These compounds may have synergistic or additional effects on total antioxidant activity. Beyond that, it could be possible that the compounds might play a role in synergistic effect with other compounds. In present study, the essential oil from aerial part and underground part are answerable to the observed antioxidant activity of $C$. phaeocaulis. The results showed that the essential oils from the underground part exhibited higher antioxidant activity than those from the aerial part ones. From the comparison of aerial part and underground part which have different physical states in the same species, the antioxidant properties in underground part showed higher accumulation.

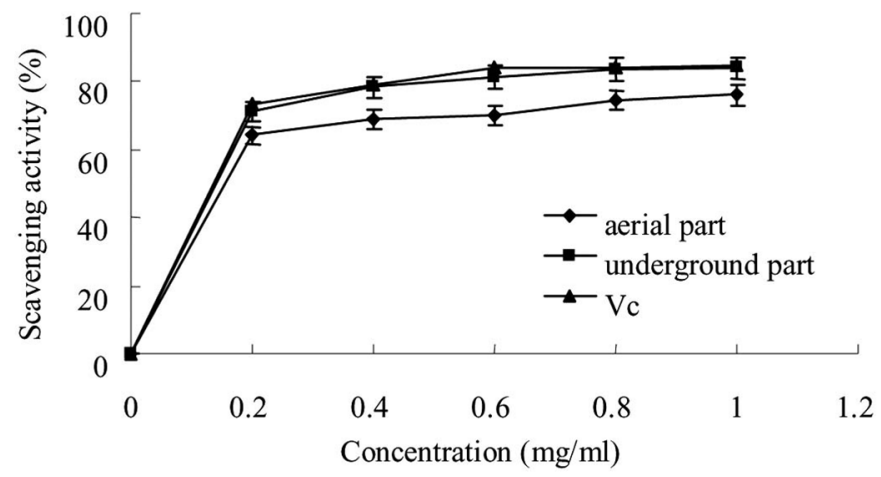

Fig. 3. Radical scavenging effect of Curcuma phaeocaulis essential oil on superoxide anion.

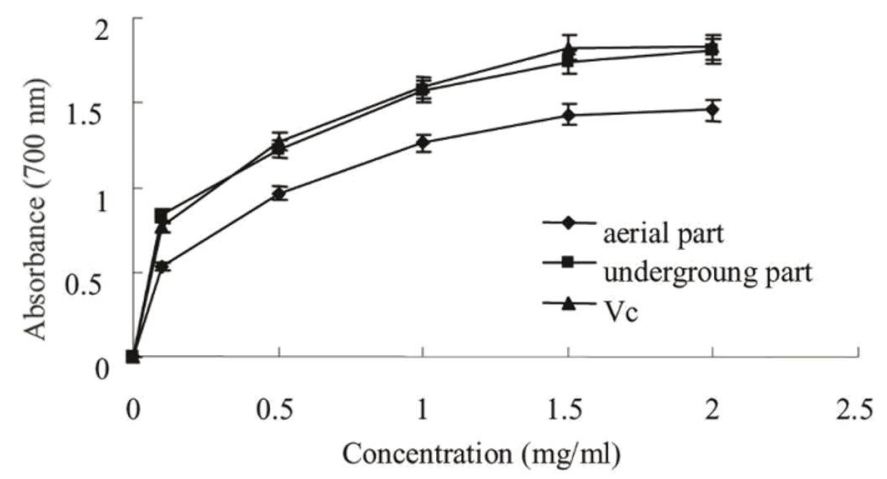

Fig. 4. $\mathrm{Fe}^{2+}$ chelating effect of Curcuma phaeocaulis essential oil.

It may be concluded that the antibacterial activities of essential oil have medicinal values. Thus, the essential oil could be utilized as an alternative source of the useful antimicrobial drugs. It could be recommended that $C$. phaeocaulis are highly important on the basis of their medicinal values. Along with the tested strains (Staphylococcus aureus, Bacillus cereus, Salmonella and Escherichia coil), other strains could be also used for further investigations for its broad aspect importance.

\section{Acknowledgments}

This work was financially supported by the R\&D Infrastructure and Facility Development Program of Sichuan (No. 2018TJPT0013). 


\section{References}

Athukorala Y, Kim KN, Jeon and YJ 2006. Antiproliferative and antioxidant properties of an enzymatic hydrolysate from brown alga, Ecklonia cava. Food Chem. Toxicol. 44: 1065-1074.

Azuine MA and Bhide SV 1992. Chemopreventive effect of turmeric against stomach and skin tumors induced by chemical carcinogenesis in Swiss mice. Nutr. Cancer. 17: 77-83.

Barclay LRC, Vinqvist MR and Mukai K 2000. Goto H. Hashimoto Y. Tokunaga A. Uno H. On the antioxidant mechanism of curcumin: classical methods are needed to determine antioxidant mechanism and activity. Org. Lett. 2(18): 2841-2843.

Chen J and Xia NH 2010. Chromosome cytology, leaf epidermal morphology and palynology of Curcuma rubrobracteata (Zingiberaceae). Nord. J. Bot. 28: 212-215.

Feng T, Wei Y, Lee RJ and Ling Z 2017. Liposomal curcumin and its application in cancer. Int. J. nanomedicine. 12: 6027.

Galano A, Tan DX and Reiter RJ 2011. Melatonin as a natural ally against oxidative stress: A physicochemical examination. J. Pineal. Res. 51(1): 1-16.

Hou Y, Lu C, Zeng QH and Jiang JG 2015. Anti-inflammatory, antioxidant and antitumor activities of ingredients of curcuma phaeocaulis val. Excli. J. 14: 706-713.

Hua D, Zhang D, Huang B, Yi P and Yan C 2014. Structural characterization and DPPH radical scavenging activity of a polysaccharide from Guara fruits. Carbohyd. Polym. 103:143-147.

Hwang JK, Shim JS and Pyun YR 2000. Antibacterial activity of xanthorrhizol from Curcuma xanthorrhiza against oral pathogens. Fitoterapia. 71(3): 321-323.

Imaida K, Fukushima S, Shivai T, Ohtani M, Nakanishi K and Ito N 1983. Promoting activities of butylated hydroxyanisole and butylated hydroxytoluene on 2-stage urinary bladder carcinogenesis and inhibition of c-glutamyl trans peptidase-positive foci development in liver of rats. Carcinogenesis 4: 885-889.

Jena S, Ray A, Banerjee A, Sahoo A, Nasim N and Nayak S 2017. Chemical composition and antioxidant activity of essential oil from leaves and rhizomes of Curcuma angustifolia Roxb. Nat. Prod. Res. 31(18): 2188-2191.

Jiang J and Xiong YL 2016. Natural antioxidants as food and feed additives to promote health benefits and quality of meat products: A review. Meat. Sci. 120: 107-117.

Jiang Y, Wang L, Zhang L, Wang T, Zhou Y and Yu L 2015. Optimization of extraction and antioxidant activity of polysaccharides from Salvia miltiorrhiza Bunge residue. Int. J. Biol. Macromol. 79: 533-541.

Kinderlerer JL and Johnson S 1992. Rancidity in hazelnuts due to volatile aliphatic aldehydes. J Sci. Food. Agric. 58(1): 89-93.

Kryston TB,Georgiev AB, Iis P and Georgakilas AG 2011. Role of oxidative stress and DNA damage in human carcinogenesis. Mutat. Res. 711(1-2): 193-201.

Liu J, Luo J, Ye H and Sun Y 2009. Production, characterization andantioxidant activities in vitro of exopolysaccharides from endophytic bacterium Paenibacillus polymyxa EJS-3. Carbohyd Polym. 78(2): 275-281.

Mahendra $P$ and Bisht S 2011. Coriandrum sativum: A daily use spice with great medicinal effect. Pharmacogn. J. 3(21): 84-88.

Mateen S, Moin S, Zafar A and Khan AQ 2016. Redox signaling in rheumatoid arthritis and the preventive role of polyphenols. Clin. Chim. Acta. 463: 4-10.

Milella L, Bader A, De Tommasi, Russo D and Braca A 2014. Antioxidant and free radical-scavenging activity of constituents from two Scorzonera species. Food Chem. 160: 298-304.

Musa KH Abdullah and A Al-Haiqi 2016. Determination of DPPH free radical scavenging activity: application of artificial neural networks. Food Chem. 194: 705-711.

Naik GH, Priyadarsini KI and Satav JG 2003. Comparative antioxidant activity of individual herbal components used in Ayurvedic medicine. Phytochemistry 63(1): 97-104.

Nevin K 2017. Curcumin an active component of turmeric (Curcuma longa), and its effects on health. Crit. Rev. Food Sci. 57(13): 2889-2895. 
Paulo L, Ferreira S and Gallardo E 2010. Queiroz JA. Domingues F. Antimicrobial activity and effects of resveratrol on human pathogenic bacteria. World J. Microb. Biot. 26(8): 1533-1538.

Prasad S and Tyagi AK 2015. Curcumin and its analogues: a potential natural compound against HIV infection and AIDS. Food. Funct. 6(11): 3412-3419.

Sathishkumar M, Sneha K andYun YS 2010. Immobilization of silver nanoparticles synthesized using Curcuma longa tuber powder and extract on cotton cloth for bactericidal activity. Bioresour. Technol. 101(20): 7958-7965.

Wilson B, Abraham G and Manju VS 2005. Antimicrobial activity of Curcuma zedoaria and Curcuma malabarica tubers. J. Ethnopharmacol. 99(1): 147-151.

Wu DL Larsen and K Zingiberaceae. 2000. In: Flora of China, vol. 24 (eds Wu ZY \& Raven P), Science Press, Beijing and Missouri Botanical Garden Press, St. Louis, MO. pp. 322-377.

Xiao XH, Shu ZW, Qiao CZ and Luo ZY 1997. Advances in the study on medicinalof Curcuma. Chin. Tradit Herb Drugs. 28(2): 114-118.

Xie J and Schaich KM 2014. Re-evaluation of the 2, 2-diphenyl-1-picrylhydrazyl free adical (DPPH) assay for antioxidant activity. J. Agr. Food Chem. 62(19): 4251-4260.

Yang XM, Yu W, Ou ZP, Ma HL, Liu WM and Ji XL 2009. Antioxidant and mmunity activity of water bgextract and crude polysaccharide from Ficus carica L. fruit. Plant Foods for Hum Nutr. 64(2): 167173.

Yuan YV, Carrington MF and Walsh NA 2005. Extracts from dulse (Palmariapalmata) are effective antioxidants and inhibitors of cell proliferation in vitro. Food Chem. Toxicol. 43: 1073-1081.

(Manuscript received on 12 April, 2019; revised on 26 July, 2019) 